\title{
Parametric optimization during machining of AISI 304 Austenitic Stainless Steel using CVD coated DURATOMIC $^{\mathrm{TM}}$ cutting insert
}

\author{
M. Kaladhar ${ }^{a^{*}}$, K. Venkata Subbaiah ${ }^{\mathrm{b}}$, Ch. Srinivasa Rao ${ }^{\mathrm{b}}$
}

\begin{tabular}{|c|c|}
\hline AR T I C L E I N F O & A B S T R A C T \\
\hline $\begin{array}{l}\text { Article history: } \\
\text { Received } 25 \text { January } 2012 \\
\text { Accepted April } 12012 \\
\text { Available online } \\
8 \text { April } 2012 \\
\text { Keywords: } \\
\text { CVD coated cemented carbide } \\
\text { Surface roughness } \\
\text { MRR } \\
\text { AISI } 304 \text { austenitic stainless steel } \\
\text { Taguchi method } \\
\text { ANOVA }\end{array}$ & $\begin{array}{l}\text { In this work, Taguchi method is applied to determine the optimum process parameters for turning } \\
\text { of AISI } 304 \text { austenitic stainless steel on CNC lathe. A Chemical vapour deposition (CVD) coated } \\
\text { cemented carbide cutting insert is used which is produced by Duratomic }{ }^{\mathrm{TM}} \text { technology of } 0.4 \text { and } \\
0.8 \mathrm{~mm} \text { nose radii. The tests are conducted at four levels of Cutting speed, feed and depth of cut. } \\
\text { The influence of these parameters are investigated on the surface roughness and material removal } \\
\text { rate (MRR). The Analysis Of Variance (ANOVA) is also used to analyze the influence of cutting } \\
\text { parameters during machining. The results revealed that cutting speed significantly ( } 46.05 \%) \\
\text { affected the machined surface roughness values followed by nose radius }(23.7 \%) \text {. The influence } \\
\text { of the depth of cut }(61.31 \%) \text { in affecting material removal rate (MRR) is significantly large. The } \\
\text { cutting speed ( } 20.40 \%) \text { is the next significant factor. Optimal range and optimal level of } \\
\text { parameters are also predicted for responses. }\end{array}$ \\
\hline
\end{tabular}

\section{Introduction}

Surface roughness is concerned to the quality of the products. A good surface finish is essential to improve fatigue strength, corrosion resistance, and aesthetical appeal. It is expressed in surface roughness value. Nowadays, manufacturing industries greatly concerned with dimensional accuracy and surface finish. The surface roughness is influenced by various factors such as the cutting tool geometry, cutting parameters, microstructure of work piece and the rigidity of the lathe, chip interface, Built-up Edge (BUE) formation, tool and work piece vibration, the way of interaction of tool with work piece etc. so that ideal surface finish is difficult to obtain because of the stated reasons (Sullivan \& Cotterell, 2002). The surface roughness is also influenced by improper selection of process parameters which further causes tool damage.

The consequences of tool damage leads to economical losses like work piece spoiling or poor surface quality. Selection of optimal process parameters using various optimization techniques will help to solve the problem of improper selection of process parameters. In order to select optimal cutting

* Corresponding author. Tel. +91-9849467339

E-mail: kaladhar2k@gmail.com (M. Kaladhar)

(C) 2012 Growing Science Ltd. All rights reserved. doi: $10.5267 /$ j.ijiec.2012.04.002 
parameters, manufacturing to obtain optimal cutting parameters, manufacturing industries have depended on the use of handbook based information which leads to decrease in productivity due to suboptimal use of machining capability. This causes high manufacturing cost and low product quality (Aggarwal \& Singh, 2005). Hence, there is a need of a systematic methodological tool for optimization of parameters. The Taguchi's parametric design is such an effective tool for robust design. Numerous experimental investigations have been carried out over the years to study the effect of cutting parameters, tool geometries on the work pieces surface integrity using several types of work piece materials. Tool geometry plays an important role in machining. It is found that the nose radius will affect the performance of the machining process (Wang \& Lan, 2008). Nose radius is a major factor that affects the surface finish of work piece. It is proved that high values of nose radius causes rough surface with high value of run out (Saad Kariem, 2009).

However, very few researchers have studied the interaction effect of nose radius (Saad kariem, 2009; Ravindra, 2008; Kishawy et al., 1997; Chou \& Song, 2004; Sundaram \& Lambert, 1981; Lambert, 1983; Bhattacharya et al., 1970; Aggarwal et al., 2008; Gokaya et al., 2007). The aim of the present experimental investigation is to evaluate the effects and optimization of process parameters on surface roughness and material removal rate (MRR) of AISI 304 austenitic stainless steel work piece during turning operation. The experimentation is carried out by using a chemical vapour deposition (CVD) coated Duratomic tool on CNC lathe under dry environment. The AISI 304 is the most widely used grades of austenitic stainless steel. It is used for aerospace components and chemical processing equipment, for food, dairy, and beverage industries, for heat exchangers, and for the milder chemicals.

\section{Literature review}

The austenitic stainless steel grade used in large volumes (72\%), compared with all other grades of stainless steels. It was reported that austenitic stainless steels belong to difficult to machine materials category because of their low thermal conductivity and high mechanical and micro structural sensitivity to strain and stress rate (M'Saoubi et al., 2008). Many of research works contributed their efforts to overcome poor machinability of austenitic stainless steels. Lin (2008) investigated surface roughness variations of different grades of austenitic stainless steel under different cutting conditions in high speed fine turning. Surface roughness and tool wear were predicted by regression analysis and ANOVA. Xavior \& Adithan (2009) determined the influence of different cutting fluids on wear and surface roughness in turning of AISI 304 austenitic stainless steel. Ciftci (2006) conducted the experiments to Machine AISI 304 and AISI 316 austenitic stainless steels using CVD multi-layer coated cemented carbide tools.

The results showed that cutting speed significantly affected the machined surface roughness values. Özek et al. (2006) investigated to determine surface roughness, tool wear and tool-chip interface temperature in turning of AISI 304. Empirical models for tool life, surface roughness and cutting force were developed for turning of AISI 302 developed by Al-Ahmari (2007). Multiple regression analysis techniques, response surface methodology and computational neural networks were used to predict models of process functions.

Caydas and Ekici (2010) used support vector machines (SVM) tools namely least square-SVM, spider SVM and an artificial neural networks (ANN) models to develop to assess the surface roughness values of AISI 304 austenitic stainless steel. Jahan et al. (2010) made an attempt to machine deep micro holes in two difficult to machine materials: WC-CO \& austenitic stainless steel SUS 304 with microEDM drilling. Sullivan \& Cotterell (2002) used an on-line Acoustic Emission (AE) analysis technique to detect the work hardening of AISI 303 austenitic stainless steel. Korkut et al. (2004) determined the optimum cutting conditions during machining of AISI 304 austenitic stainless steel. Probably this was the first attempt to determine the optimum cutting conditions during machining of AISI 304 austenitic stainless steel. Akasawa et al. (2003) conducted experiments to determine the effect of variations of the 
contents of additives $\mathrm{S}, \mathrm{Ca}, \mathrm{Cu}$ and $\mathrm{Bi}$ on the machinability of various grades of 300 series of austenitic stainless steel. Jukka Paro et. al. (2001) selected to turn X5 CrMnN 18/8 stainless steels material to turn, to investigate its machinability with $\mathrm{TiN}$ and $\mathrm{Al}_{2} \mathrm{O}_{3}$ coated carbide inserts. The literature survey revealed that little attention has been focused to turn the AISI 304 austenitic stainless steel under different cutting parameters.

\section{Material and Methods}

\subsection{Methodologies: Taguchi approach}

Taguchi's parametric design is an effective tool for robust design. It offers a simple and systematic qualitative optimal design at a relatively low cost. It has been widely used for the last two decades. The greatest advantage of this approach is to save the experimental time as well as the cost by finding out the significant factors by analysis. One of the important steps involved in Taguchi's technique is selection of an orthogonal array (OA). An OA is a small set from all possibilities which helps to determine least number of experiments, which will further help to conduct experiments to determine the optimum level for each process parameters and establish the relative importance of individual process parameters. To obtain optimum process parameters setting, Taguchi proposed a statistical measure of performance called signal to noise ratio $(\mathrm{S} / \mathrm{N}$ ratio). This ratio considers both the mean and the variability. In addition to $\mathrm{S} / \mathrm{N}$ ratio, ANOVA is used to indicate the influence of process parameters on performance measures. Taguchi proposed three categories of performance characteristics in the analysis of the $\mathrm{S} / \mathrm{N}$ ratio, that is, the smaller the better, the higher the better, and the nominal the better (Ross, 1996). Numerous researchers have used Taguchi method to materials processing for process optimization (Singh, 2008; Singh \& Kumar, 2003; Anrin et al., 2009; Barua et al., 1997; Mahapatra et al., 2006; Thamizhmanii et al., 2007; Lan, 2009). In the present work, the first criterion selects thesmaller-the-better characteristic of the surface roughness and larger the better type for MRR. Smaller the better type $\mathrm{S} / \mathrm{N}$ ratio for $\mathrm{R}_{\mathrm{a}}, \quad\left[\eta_{1}\right]=-10 \log _{10}\left[R_{a}^{2}\right]$, the larger the better type $\mathrm{S} / \mathrm{N}$ ratio for MRR, $\left[\eta_{2}\right]=-10 \log _{10}\left[\frac{1}{M R R^{2}}\right]$.

\subsection{Experimental}

Turning is a popularly used machining process in which a single point cutting tool removes unwanted material from the surface of a rotating cylindrical work piece. The computer numerical controlled (CNC) machines play a major role in modern machining industry to enhance product quality as well as productivity (Tian-Syung, 2009). The machining tests are carried out on the material in cylindrical form, $330 \mathrm{~mm}$ long and $50 \mathrm{~mm}$ diameter by two layer CVD of grade TP $2500 \mathrm{Ti}(\mathrm{C}, \mathrm{N})+\mathrm{Al}_{2} \mathrm{O}_{3}$ coated cemented carbide inserts of two different nose radii on Parishudh TC-250 CN, India, CNC lathe with a variable speed of up to $3250 \mathrm{rpm}$ and a power rating of $7.5 \mathrm{~kW}$. A center hole was drilled on the face of the work piece to allow supporting at the tailstock (Fig. 1).

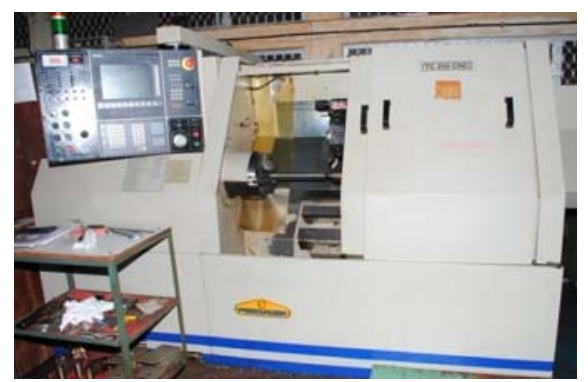

Fig. 1 Experimental set-up 
These work pieces were cleaned prior to the experiments by removing $0.3 \mathrm{~mm}$ thickness of the top surface from each work piece in order to eliminate any surface defects and wobbling. The surface roughness of machined surfaces has been measured by a Talysurf (Taylor Hobson, Surtronic 3+, UK) surface roughness tester. The chemical composition of AISI 304 is given in Table 1. The present experimental investigation is carried out according to the Taguchi's L16 mixed level design as shown in the Table 3.

Table 1

Chemical composition of AISI 304

\begin{tabular}{cccccccccccccc}
\hline Elements & $\mathrm{C}$ & $\mathrm{Si}$ & $\mathrm{Mn}$ & $\mathrm{Cr}$ & $\mathrm{Ni}$ & $\mathrm{Mo}$ & $\mathrm{Cu}$ & $\mathrm{Ti}$ & $\mathrm{V}$ & $\mathrm{W}$ & $\mathrm{Co}$ & $\mathrm{Nb}$ & $\mathrm{Fe}$ \\
\hline Composition(\%wt) & 0.051 & 0.412 & 1.351 & 18.275 & 8.473 & 0.301 & 0.318 & 0.005 & 0.049 & 0.003 & 0.019 & 0.020 & Balance \\
\hline
\end{tabular}

Table 2

Process parameters levels

\begin{tabular}{llcccc}
\hline & & \multicolumn{3}{c}{ Levels } \\
\hline Symbol & parameters & 1 & 2 & 3 & 4 \\
A & Cutting speed $(\mathrm{m} / \mathrm{min})$ & 150 & 170 & 190 & 210 \\
B & Feed $(\mathrm{mm} / \mathrm{rev})$ & 0.15 & 0.20 & 0.25 & 0.30 \\
$\mathrm{C}$ & Depth of cut $\mathrm{mm})$ & 0.5 & 1.0 & 1.5 & 2.0 \\
D & Nose radius $(\mathrm{mm})$ & 0.4 & 0.8 & \\
\hline
\end{tabular}

\section{Table 3}

$\mathrm{L}_{16}$ mixed level design

\begin{tabular}{ccccccc}
\hline Trail no. & $\begin{array}{c}\text { Cutting Speed } \\
\text { A }\end{array}$ & $\begin{array}{c}\text { Feed } \\
\text { B }\end{array}$ & $\begin{array}{c}\text { Depth of Cut } \\
\text { C }\end{array}$ & $\begin{array}{c}\text { Nose radius } \\
\mathrm{D}\end{array}$ & $\begin{array}{c}\text { Surface roughness } \\
\mathrm{R}_{\mathrm{a}}(\mu \mathrm{m})\end{array}$ & $\begin{array}{c}\text { Material removal rate } \\
\left(\mathrm{mm} / \mathrm{min}^{3}\right)\end{array}$ \\
\hline 1 & 1 & 1 & 1 & 1 & 1.425 & 12291.67 \\
2 & 1 & 2 & 2 & 1 & 2.363 & 24452.55 \\
3 & 1 & 3 & 3 & 2 & 1.06 & 33141.45 \\
4 & 1 & 4 & 4 & 2 & 0.867 & 33645.37 \\
5 & 2 & 1 & 2 & 2 & 2.432 & 11369.05 \\
6 & 2 & 2 & 1 & 2 & 1.515 & 9537.037 \\
7 & 2 & 3 & 4 & 1 & 3.33 & 40492.96 \\
8 & 2 & 4 & 3 & 1 & 1.332 & 37328.38 \\
9 & 3 & 1 & 3 & 1 & 1.75 & 48112.86 \\
10 & 3 & 2 & 4 & 1 & 2.332 & 83250.25 \\
11 & 3 & 3 & 1 & 2 & 1.992 & 12592.59 \\
12 & 3 & 4 & 2 & 2 & 0.962 & 26890.76 \\
13 & 4 & 1 & 4 & 2 & 1.017 & 30434.78 \\
14 & 4 & 2 & 3 & 2 & 2.932 & 26715.69 \\
15 & 4 & 3 & 2 & 1 & 1.295 & 27085.75 \\
16 & 4 & 4 & 1 & 1 & 10641.89 \\
\hline
\end{tabular}

\subsection{Cutting tool and cutting conditions}

About $70 \%$ of the industries use coated cemented carbide tools. Because coated carbide tools have shown better performance when compared with the uncoated carbide tools (Noordin et al., 2004). For this reason, available CVD of grade TP $2500 \mathrm{Ti}(\mathrm{C}, \mathrm{N})+\mathrm{Al}_{2} \mathrm{O}_{3}$ coated cemented carbide inserts of 0.8 and $0.4 \mathrm{~mm}$ as nose radius are used in the present experimental investigation. TP- 2500 is the first grade created with the DurAtomic technology by SECO tool manufacturers. The DurAtomic technology produces chemically alter crystal structure of the aluminum-oxide $\left(\mathrm{Al}_{2} \mathrm{O}_{3}\right)$ layer to create the coating that offers a high surface finish, less tool wear, greater tool life and speed capability. These advantages are particularly important in stainless steel machining (Seco tools). Duratomic coating is superior to traditional coatings because of its atomic structure. The DurAtomic coating has a TiCN lower layer topped by the new $\mathrm{Al}_{2} \mathrm{O}_{3}$. The Process parameters and levels used in the experiment are given in the 
Tables 2. The cutting parameters levels are selected according to the recommendations of the cutting inserts manufacturer (Seco tools).

\subsection{Calculation of Material Removal Rate}

Material removal rate (MRR) has been calculated from the difference of weight of work piece before and after experiment by using the following formula. Where, $W_{i}$ is the initial weight of work piece in grams ; $W_{f}$ is the final weight of work piece in grams; $t$ is the machining time in minutes; $\rho_{s}$ is the density of AISI 304 austenitic stainless steel $\left(8 \times 10^{-3} \mathrm{~g} / \mathrm{mm}^{3}\right)$.

$$
M R R=\frac{W_{i}-W_{f}}{\rho_{s} t} \mathrm{~mm}^{3} / \mathrm{min}
$$

\section{Results and discussion}

Experiments are conducted to investigate the effects of cutting parameters on the surface roughness and MRR of the AISI 304 austenitic stainless steel work pieces. Table 3 gives experimental results. While estimating the mean and confidence interval, interaction effects are not taken in to account.

\subsection{Analysis of variance (ANOVA)}

The present work used ANOVA to determine the optimum combination of process parameters more accurately by investigating the relative importance of process parameters. Table 4 presents the results of ANOVA for surface roughness $(\mathrm{Ra})$. It is observed from the ANOVA table, the cutting speed $(46.05 \%)$ is the most significant parameter followed by nose radius $(23.7 \%)$. However, the depth of cut has the least effect $(13.28 \%)$ in controlling the surface roughness. Statistically, F-test decides whether the parameters are significantly different. A larger $\mathrm{F}$ value shows the greater impact on the machining performance characteristics (Ross, 1996). Larger F-values are observed for speed as 3.512 and nose radius as 5.424. As seen from the ANOVA Table 5, the influence of the depth of cut $(61.31 \%)$ in affecting material removal rate (MRR) is significantly large. The cutting speed $(20.40 \%)$ is the next significant factor. However, the feed has least effect (5.38\%) in producing MRR.

\section{Table 4}

ANOVA results for surface roughness

\begin{tabular}{llllll}
\hline Source & SS & DOF & MS & F & C (\%) \\
\hline Cutting speed & 5.184 & 3 & 1.728 & 3.512195 & 46.05 \\
Feed & 1.909 & 3 & 0.636 & 1.292683 & 16.96 \\
Depth of Cut & 1.495 & 3 & 0.498 & 1.012195 & 13.28 \\
Nose radius & 2.669 & 1 & 2.669 & 5.424797 & 23.70 \\
Error & 2.462 & 5 & 0.492 & & \\
Total & 8.796 & 15 & & & \\
\hline
\end{tabular}

Table 5

ANOVA results for MRR

\begin{tabular}{llllll}
\hline Source & SS & DOF & MS & F & C (\%) \\
\hline Cutting speed & 976029752 & 3 & 325343251 & 4.333984 & 20.40469 \\
Feed & 257782508 & 3 & 85927503 & 1.144663 & 5.389153 \\
Depth of cut & 2932898611 & 3 & 977632870 & 13.02331 & 61.31463 \\
Nose radius & 616647879 & 1 & 616647879 & 8.214531 & 12.89152 \\
Error & 375339678 & 5 & 75067935.57 & & \\
Total & 4408019072 & 15 & & & \\
\hline SS= Sum of squares; DOF= Degree of freedom; MS= Mean squares C=contribution
\end{tabular}

\subsection{Main effect plots analysis}


The analysis is made with the help of a software package MINITAB 14. The main effect plots are shown in Fig.2 and Fig.3.These show the variation of individual response with the four parameters i.e. cutting speed, feed, depth of cut and nose radius separately. In the plots, the x-axis indicates the value of each process parameter at two level and y-axis the response value. Horizontal line indicates the mean value of the response.

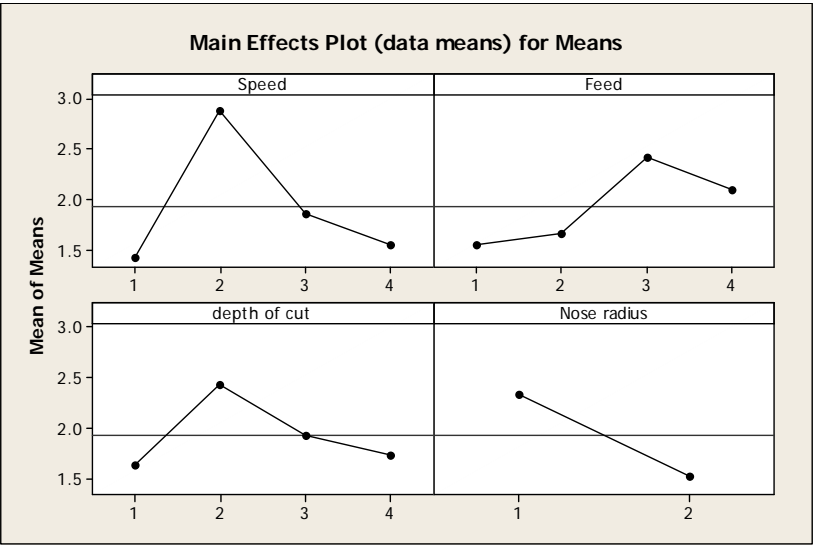

Fig. 2. Main effect plot for Surface roughness

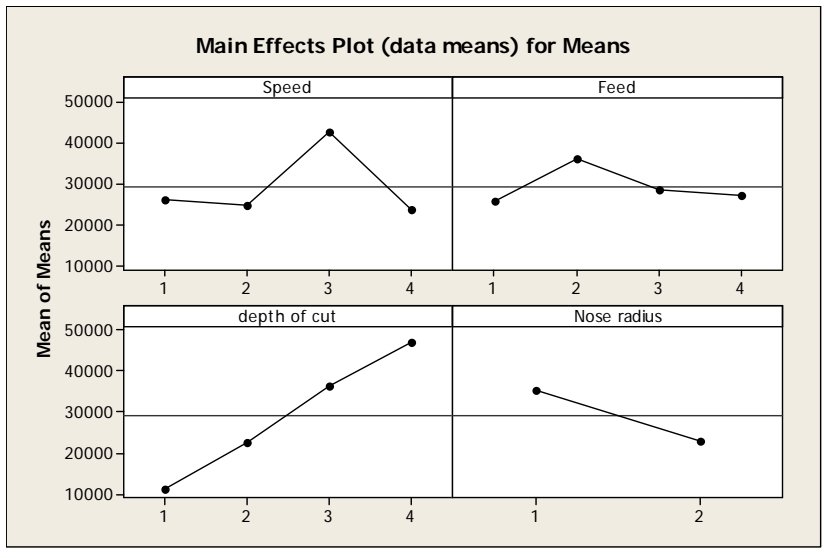

Fig.3 Main effect plot for MRR

The main effects plots are used to determine the optimal design conditions to obtain the optimum surface finish. Fig.2 shows the main effect plot for surface roughness. According to this main effect plot, the optimal conditions for minimum surface roughness are:

- Cutting speed at level $1(150 \mathrm{~m} / \mathrm{min})$,

- Feed rate at level $1(0.15 \mathrm{~mm} / \mathrm{rev})$,

- Depth of cut at level $1(0.5 \mathrm{~mm})$,

- Nose radius level $2(0.8 \mathrm{~mm})$

According to main effect plot Fig. 3, the optimal conditions for maximum MRR are:

- Cutting speed at level $3(190 \mathrm{~m} / \mathrm{min})$,

- Feed rate at level $2(0.20 \mathrm{~mm} / \mathrm{rev})$,

- Depth of cut at level $4(2.0 \mathrm{~mm})$,

- Nose radius level $1(0.4 \mathrm{~mm})$

\subsection{Prediction of optimal design}

Performance of $R_{a}$ when the two most significant factors are at their best level (based on estimated average)

$$
\begin{gathered}
\left.\bar{\mu}_{A_{1} B_{1}}=\bar{A}_{1}+\bar{B}_{1}-\bar{T}=1.429+1.551-1.930=1.05 \text { (From Table } 3, \bar{T}=1.930\right) . \\
C I=\sqrt{\frac{F_{95 \%, 1, d o f_{\text {error }}}{ }^{*} V_{\text {error }}}{n_{\text {efficiency }}}},
\end{gathered}
$$

where $n_{\text {efficiency }}=\mathrm{N} /(1+d o f)$ of all parameters associated to that level,

$$
n_{\text {efficiency }}=16 /(1+3+3)=2.2857, V_{\text {error }}=2.462(\text { from Table } 4), F_{95 \%, 1,5}=6.61(\text { From F-table })
$$




$$
C I=\sqrt{6.61 \times 2.462 / 3.2}=2.255
$$

The predicted optimal range of $\mathrm{R}_{\mathrm{a}}$ at $95 \%$ confidence level is obtained as,

Table 6

$$
\begin{aligned}
1.05-2.255 \leq \bar{\mu}_{A_{1} B_{1}} & \leq 1.05+2.255 \\
-1.205 & \leq \bar{\mu}_{A_{1} B_{1}} \leq 3.305
\end{aligned}
$$

Mean Values of surface roughness (Ra)

\begin{tabular}{ccccc}
\hline level & speed & feed & depth of cut & nose radius \\
\hline 1 & 1.429 & 1.551 & 1.642 & 2.339 \\
2 & 2.877 & 1.661 & 2.430 & 1.522 \\
3 & 1.865 & 2.414 & 1.924 & \\
4 & 1.552 & 2.097 & 1.727 & \\
\hline
\end{tabular}

Performance of MRR when the two most significant factors are at their best level (based on estimated average)

$$
\begin{gathered}
\left.\bar{\mu}_{A_{3} D_{4}}=\bar{A}_{3}+\bar{D}_{4}-\bar{T}=42712+46956-29248.94=60419.06 \text { (From Table } 3, \bar{T}=29248.94\right) . \\
C I=\sqrt{\frac{F_{95 \%, 1, \text { doferror }}{ }^{*} V_{\text {error }}}{n_{\text {efficiency }}}} ;
\end{gathered}
$$

where $n_{\text {efficiency }}=\mathrm{N} /(1+d o f)$ of all parameters associated to that level, $n_{\text {efficiency }}=16 /(1+1+3)=3.2$, $V_{\text {error }}=375339678$ (from Table 4), $F_{95 \%, 1,5}=6.61$ (From F-table) $C I=\sqrt{6.61 \times 375339678 / 3.2}=27844.47$.

The predicted optimal range of MRR at $95 \%$ confidence level is obtained as, $32574.65 \leq \bar{\mu}_{A_{3} D_{4}} \leq 88263.46$.

Table 7

Mean Values of MRR

\begin{tabular}{ccccc}
\hline level & speed & feed & depth of cut & nose radius \\
\hline 1 & 25883 & 25552 & 11266 & 35457 \\
2 & 24682 & 35989 & 22450 & 23041 \\
3 & 42712 & 28328 & 36325 & \\
4 & 23720 & 27127 & 46956 & \\
\hline
\end{tabular}

\subsection{Mathematical modeling}

A multiple linear regression model was developed for surface roughness and MRR using Minitab-14 software. The predictors are cutting speed, feed, depth of cut and nose radius. The regression equation is $\mathrm{Ra}=2.78-0.064 *$ Speed $+0.239 *$ Feed $-0.025 *$ depth of cut $-0.817 *$ Nose radius. The regression equation is MRR $=15486+1154 *$ Speed $-294 *$ Feed $+12095 *$ depth of cut $-12416 *$ Nose radius.

The diagnostic checking has been performed through residual analysis for the developed models. The residual plots for surface roughness and MRR are shown in Fig. 4-7. These are generally fall on a straight line implying that errors are distributed normally. From Fig. 4-7 it can be concluded that all the values are within the CI level of $95 \%$. Hence, these values yield better results in future prediction. Fig. $5 \& 7$ indicated that there is no obvious pattern and unusual structure. From the Fig. 4-7, it can be concluded that the residual analysis does not indicate any model inadequacy. 


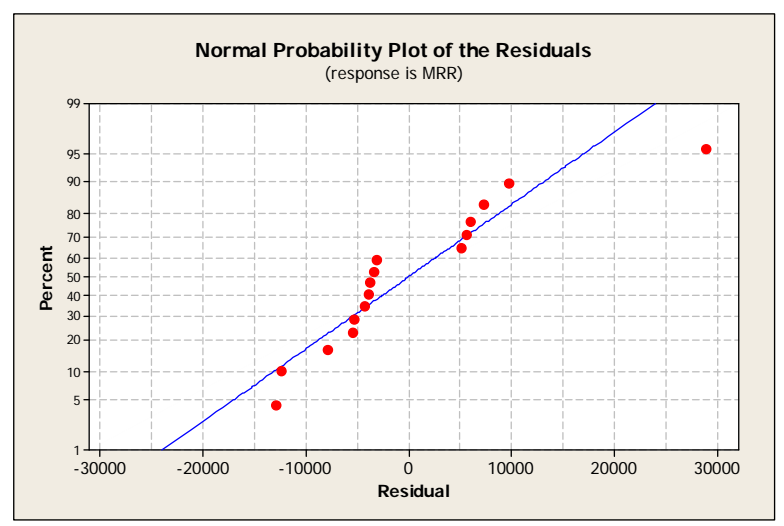

Fig. 4. Normal Probability of the residuals for MRR

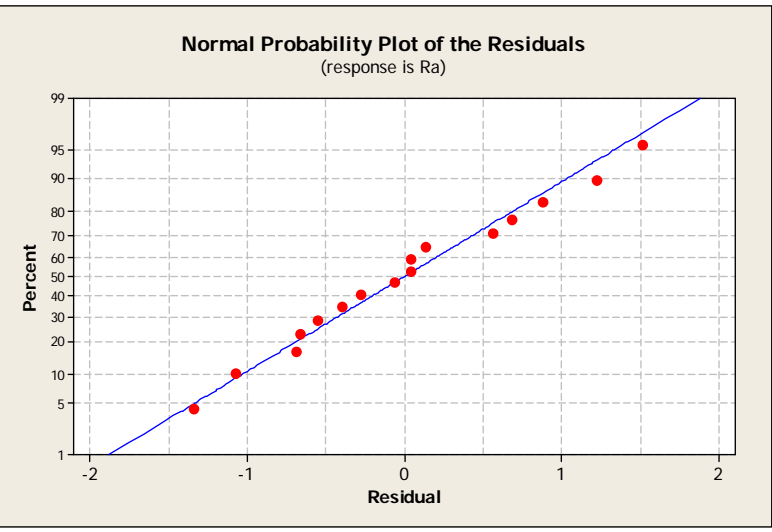

Fig. 6. Normal Probability of the residuals for Surface roughness

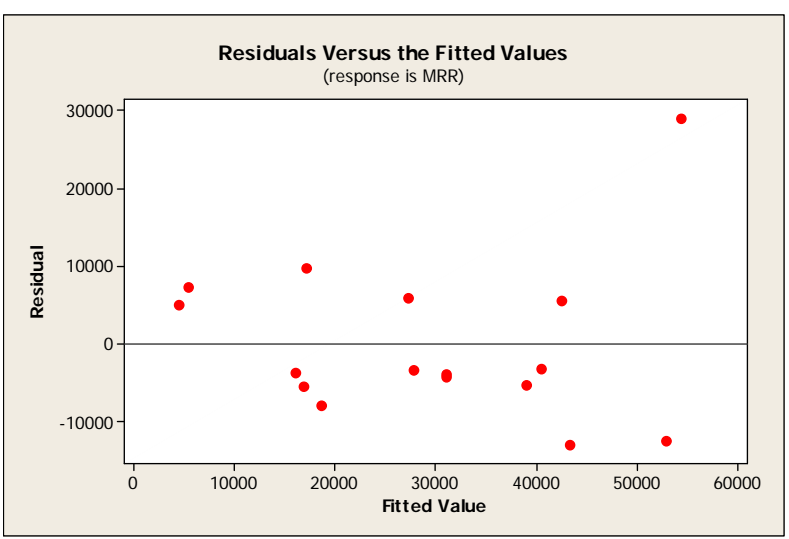

Fig. 5. Residuals versus the fitted values for MRR

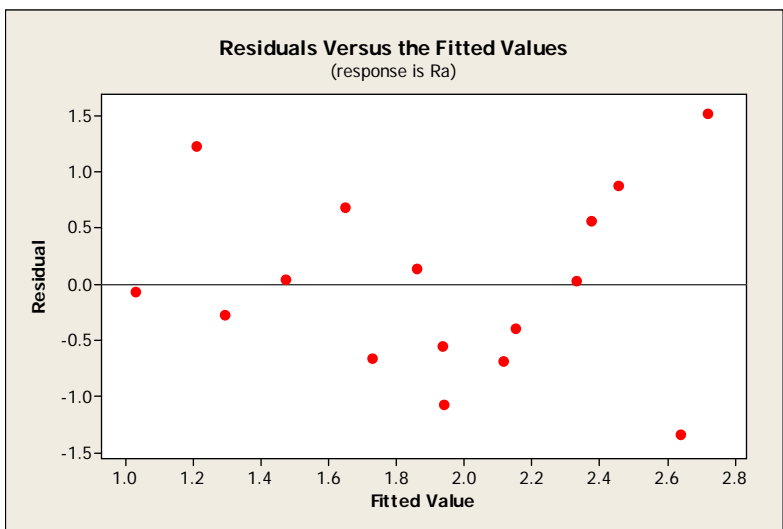

Fig. 7. Residuals versus the fitted values for Surface roughness

\section{Conclusions}

The experimental investigation was conducted to turn AISI 304 austenitic stainless steel using CVD coated cemented carbide Duratomic cutting insert at four levels of cutting parameters by employing Taguchi technique to determine the optimal levels of process parameters. The ANOVA and F-test revealed that the cutting speed is the dominant parameter followed by nose radius for surface roughness. In case of MRR response, the depth of cut is the dominant one followed by the feed. The optimal combination of process parameters for minimum surface roughness is obtained at $150 \mathrm{~m} / \mathrm{min}$ cutting speed, $0.15 \mathrm{~mm} / \mathrm{rev}$ feed, $0.5 \mathrm{~mm}$ depth of cut and $0.8 \mathrm{~mm}$ nose radius. The optimal combination of process parameters for maximum MRR is obtained at $190 \mathrm{~m} / \mathrm{min}$ cutting speed, 0.20 $\mathrm{mm} / \mathrm{rev}$ feed, $2.00 \mathrm{~mm}$ depth of cut and $0.4 \mathrm{~mm}$ nose radius. A number of multiple linear regression models were developed for surface roughness and MRR. The developed models are reasonably accurate and can be used for prediction within limits. The Optimal range of surface roughness and MRR of the work piece is also predicted.

\section{References}

Akasawa, T., Sakurai, H., Nakamura, M., Tanaka, T., \& Takano, K. (2003). Effects of free-cutting additives on the machinability of austenitic stainless steels. Journal of Material Processing Technology, 143/144, 66-71.

Al-Ahmari, A.M.A. (2007). Predictive machinability models for a selected hard material in turning operations. Journal of Material Processing Technology, 190, 305-311. 
Aggarwal, A. \& and Singh, H. (2005). Optimization of machining techniques - A retrospective and Literature Review. Sadhana, 30, 699-711.

Bhattacharya, A., Das, S., Majumdar, P., \& Batish, A. (2009). Estimation of the effect of cutting parameters on surface finish and power consumption during high speed machining of AISI 1045 steel using Taguchi design and ANOVA. Production Engineering and Research Development, 3, 31-40.

Xavior, A., \& Adithan, M. (2009). Determining the influence of cutting fluids on tool wear and surface roughness during turning of AISI 304 austenitic stainless steel. Journal of Material processing Technology, 209, 900-909.

Barua, P.B., Kumar, P., \& Gaindhar, J.L. (1997). Optimal setting of process parameters for lti characteristic products using Taguchi design and utility concept-an approach. Proc ICAMIE, University of Roorkee, India, 839-842.

Bhattacharya, A., Faria-Gonzalez, R., \& Ham(1997). Regression analysis for predicting surface finish and its application in the determination of optimum machining conditions. ASME Journal of Engineering for Industry, 4, 711-714.

Özek, C., Çaydaş, U., \& Ünal, E. (2006). Turning of AISI304 austenitic stainless steel. Journal of Engineering and Natural sciences, 2, 117-121.

Chou,Y.K., \& Song, H. (2004). Tool nose radius effects on finish hard turning. Journal of Materials Processing Technology, 148(2), 259-268.

O’Sullivan, D., \& Cotterell, M. (2002). Machinability of austenitic stainless steel SS 303. Journal of Materials Processing Technology, 124, 153-159.

Singh, H., \& Kumar, P.(2003). Quality optimization of turned parts (En 24 Steel) by Taguchi method. Productivity Journal, 44, 43-48.

Singh, H. (2008). Optimizing Tool life of Carbide Inserts for Turned parts using Taguchi's Design of Experiment Approach. Proceedings of International Multi Conference of Engineering and Computer Scientists, Hong Kong, 19-21.

Gokkaya, H., \& Nalbant, M. (2007). The effect of cutting tool geometry and processing parameters on the surface roughness of AISI 1030 steel. Materials and Design, 28, 717-721.

Ciftci, I. (2006). Machining of austenitic Stainless steels using CVD multi-layer Coated cemented carbide tools. Tribology International, 39(6), 565-569.

Jukka, P., Hanninen, H., \& Kauppinen, V. (2001). Tool wear and machinability of X5 CrMnN 18 /8 stainless steels. Journal of Material Processing Technology, 119, 14-20.

Kishawy, H.A., \& Elbestawi M.A. (1997). Effect of process parameters on chip morphology. Manufacturing Science and Technology, 6, 13-20.

Korkut, I., Kasap, M., Ciftci, I., \& Seker (2004 ). Determination of optimum cutting parameters during machining of AISI 304 austenitic stainless steel. Materials and Design, 25, 303-305.

Lambert, B.K. (1983). Determination of metal removal rate with surface finish Restriction. Carbide And Tool Journal, 23,16-19.

Lan, T.S. (2009). Taguchi optimization of Multi objective CNC machining using TOPSIS. International Technology journal, 8(6), 917-922.

Lin, W.S. (2008). The study of high speed fine turning of austenitic stainless steel. Journal of Achievements in Materials and Manufacturing, 27,191-194.

Mahapatra, S.S. (2006). Parametric analysis and Optimization of cutting parameters for turning operations based on Taguchi method. Proceedings of the International Conference on Global Manufacturin and Innovation, Coimbatore, India, 1-8.

M'saoubi, R. (2008). A review of surface integrity in machining and its impact on functionalperformance and life of machined products. International Journal of Sustainable Manufacturing, 1(1/2), 203 -236.

Jahan, M.P., Wong, Y.S., \& Rahman, M. (2010). A comparative experimental investigation of deephole micro-EDM drilling capability for cemented carbide (WC-Co) against austenitic stainless steel (SUS 304). International Journal of Advanced Manufacturing Technology, 46,1145-1160. 
Ravindra, T. (2008). Comparison between Multiple Regressions Models to Study Effect of Turning Parameters on the Surface Roughness. Proceedings of the 2008 IAJC-IJME International Conference, USA, 1-12.

Ross, P.J. (1996). Taguchi Techniques for Quality Engineering. McGraw-Hill Book Company, New York.

Saad kariem, S. (2009). Studying the effect of Tool nose radius on work piece run out and surface finish. Engineering and Technology journal, 27(2), 256-261.

Sundaram, R.M., \& Lambert, B.K. (1981). Mathematical models to predict surface finish the Fine turning of Steel. International journal of production Research, 19, 547- 564.

Thamizhmanii, S., Saparudin, S., \& Hasan, S. (2007). Analyses of surface roughness by turning process using Taguchi method. Journal of Achievements in Materials and Manufacturing, 20(2), 503-506.

Çaydas, U., \& Ekici, S. (2010) Support vector machines models for surface roughness predictionin CNC turning of AISI 304 austenitic stainless steel. Journal of Intelligence Manufacturing; DOI 10.1007/s10845-010-0415-2.

Wang, M.Y., \& Lan, T.S. (2008). Parametric optimization on multi objective precision turning using grey relational analysis. International Technology journal, 7, 1072-1076.

www.seco.tools.com 